\title{
PESQUISA PARTICIPANTE: METODOLOGIA PEDAGÓGICA ALTERNATIVA PARA ENFERMEIROS*
}

Lélia Maria Madeira**

\begin{abstract}
RESUMO. Através das etapas da pesquisa participante, considerando-se os princípios da ação democrática e utilizando-se da discussão em grupo, estudou-se a problemática da hospitalização da criança, com primeiro enfoque na admissão. A análise crítica do processo evolutivo da pesquisa mostrou que a vivência do processo educativo-participativo promoveu nos enfermeiros, seja individualmente ou como grupo social, uma progressiva ascensão de sua visão da realidade, com evidente superação de uma consciência ingênua, espontânea, para outra mais crítica, reflexiva, ainda que não se tenha atingido o nível desejado de uma consciência de classe.
\end{abstract}

ABSTRACT. In this paper, made up with a group of nurses from a governamental school hospital, the methodology used was that of the participating research, taking the praxis philosophy as a theoretic reference. The children hospitalization problem was discussed in the group throughout the principles of the democracy emphasising the admission. But other necessities arouse using the historical dialectical approaching. They will be studied continually. The critical analysis of the problem showed us that the nurses made a great progress individually or as a group, in their view of the reality. They gained a more reflexive and critical class conscience despite until begining.

\section{INTRODUC̣ÃO}

Este trabalho surgiu, inicialmente, devido ao nosso interesse em reestudar a admissão da criança. Pela nossa vivência profissional sabíamos da importância deste momento para a criança e conhecíamos as deficiências assistenciais e a pouca ou nenhuma atuação do enfermeiro.

Para nós, também era importante que o trabalho a ser realizado não se limitasse apenas ao meio acadêmico e que pudesse ser útil aos pesquisados, promovendo alguma mudança na situação enfocada.

Através de nossa orientadora ficamos conhecendo a metodologia de pesquisa participante e à medida que aprofundávamos esse conhecimento, mais premente ia ficando para nós a necessidade de sua utilização na pesquisa a ser empreendida.

A pesquisa participante é uma metodologia ainda pouco utilizada, principalmente, na área da saúde. Neste método há um compromisso mútuo entre pesquisador e pesquisados; a pesquisa é feita "junto" e os pes- quisados participam em todo o processo, deixando assim de serem "objeto" para serem o "sujeito" de pesquisa.

Esta metodologia tem suas bases na filosofia da práxis, dentro do referencial epistemológico do materialismo dialético histórico, onde procura ver o homem em sua totalidade, acreditando em suas potencialidades e em sua capacidade para criar e transformar sua própria história (GRAMSCI, 1978). Também não se perde de vista a interação necessária entre conhecimento e ação, ou seja, entre teoria e prática.

Atualmente vários trabalhos têm sido realizados nesta linha de pesquisa. Apesar dos enfoques diversos, todos seguem os mesmos princípios, destacandose a ação educativa e a participação, visando sempre a mudança de uma consciência ingênua para outra mais crítica, no sentido de se conseguir melhores condições de vida.

Sobre as idéias centrais do método, no artigo do Instituto de Ação Cultural (IDAC, 1978, p. 14-39), afirmase que, o pesquisador, ao invés de se preocupar com

\footnotetext{
* Dissertação de mestrado apresentada à Escola de Enfermagem da USP. 1985.

** Professora Assistente de Enfermagem da Escola de Enfermagem da UFMG.
} 
as explicações dos fatos que acontecem, tentará, através da ação e da pesquisa, fazer brotar no grupo uma compreensão do processo de mudança que está experimentando, capacitando-o, assim, a redefinir e aprofundar a visão de sua ação conjunta.

0 processo participativo só vai ser possível através da ação educativa onde se procura valorizar a pessoa do outro; priorizar as necessidades do grupo e o conhecimento é adquirido através da descoberta e da participação. Tanto o pesquisador quanto o grupo envolvido, desvendando sua realidade, interagem e se ensinam mutuamente.

Para VALLE (1982), o trabalho desenvolvido através da ação educativa deve permitir uma aprendizagem partilhada pela população e equipe de saúde, onde haja troca de informação, capacitando o grupo a analisar criticamente sua situação, identificar e priorizar problemas, indicando soluções e se organizando para promover as soluções.

Em relação à ação educativa como processo de capacitação de indivíduos e grupos para assumirem a solução dos problemas de saúde, MENDONÇA (1982, p. 9) diz que ele deve incluir também o crescimento dos profissionais de saúde, através da reflexão conjunta sobre $o$ trabalho que desenvolvem e suas relações com a melhoria das condições da saúde da população.

Já PINTO (1982) ressalta que o profissional da saúde deve superar sua formação academicista e alcançar uma compreensão mais totalizadora, mais global da realidade, dentro da qual se insere a problemática da saúde.

Considerando-se as características da metodologia descritas acima e, conhecendo a problemática da assistência à criança hospitalizada, optamos pela utilização, neste trabalho, da pesquisa participante. A nosso ver, somente um trabalho educativo-participativo poderia levar o grupo de enfermeiros a uma atuação efetiva junto à criança hospitalizada.

Elaboramos o projeto e iniciamos a 1? etapa dando principal enfoque à admissão da criança. Posteriormente, percebemos que, se queríamos um trabalho dentro de uma visão dialética histórica, com análise crítica e compreensão dos fenômenos em sua totalidade, teríamos que ampliar tanto o tema quanto nossa população.

Decidimos ampliar a abordagem (hospitalização da criança) e conhecer melhor as percepções dos elementos da enfermagem que lidam mais diretamente com a criança.

\section{LOCAL E COMPONENTES DO GRUPO}

0 trabalho foi realizado com o grupo de enfermeiros da unidade pediátrica do Hospital de Clínicas da UFMG - Belo Horizonte - MG. Esta unidade possui 52 leitos em 2 alas.
Nas etapas iniciais da pesquisa houve grande rodízio de pessoal, coincidindo com a crise porque passava o Serviço de Enfermagem. $\mathrm{Na} 1^{\text {a }}$ etapa tínhamos 9 enfermeiros com 2 licenciados. Até a $4^{\mathrm{a}}$. etapa houve 1 demissão, 3 transferências e 5 admissões. Tínhamos assim 10 enfermeiros, com 2 licenciados.

O presente trabalho foi empreendido visando os seguintes objetivos.

\section{OBJETIVOS}

- Conhecer a problemática da assistência de enfermagem à criança hospitalizada, destacando a percepção do enfermeiro;

- Verificar transformações ocorridas, individualmente ou no grupo, mediante a utilização da metodologia de pesquisa participante.

\section{ETAPAS DA PESQUISA}

Para LE BOTERF (1984) não existe um modelo único de pesquisa participante. 0 importante é adaptar o processo às condições particulares de cada situação concreta. Neste trabalho, utilizamos o modelo recomendado no artigo do Instituto de Ação Cultural IDAC (1978). Para estes autores a Pesquisa Participante possui 4 etapas que são:

- inserção do pesquisador no grupo

- coleta de dados

- organização de dados

- devolução do material ao grupo.

$\mathrm{Na}$ pesquisa empreendida estas etapas aconteceram da seguinte forma:

\subsection{Inserção do pesquisador no grupo}

Fizemos contato com chefias de enfermagem do hospital (autorização) e com enfermeiros e auxiliares de enfermagem da pediatria (interesse pelo trabalho). Fizemos esclarecimentos necessários e perguntamos: "O que você acha do trabalho proposto?"

Passamos 5 dias na unidade (manhã, tarde e noite). Fizemos observações assistemáticas do processo de admissão da criança e após, às pessoas envolvidas fizemos uma entrevista não estruturada com pergunta aberta: "O que você acha da admissão da criança?"

Ao final, realizamos uma reunião com os enfermeiros para reafirmarmos $o$ interesse sobre $o$ assunto e $o$ compromisso com a pesquisa. Neste encontro, aparentemente, confirmamos o interesse sobre 0 assunto e 0 compromisso para fazermos o trabalho juntos.

Com as observações das admissões, através das conversasinformais com as pessoas da enfermagem e com o conhecimento prévio sobre a questão, foi possível traçar um perfil provisório da admissão da criança nesta unidade. 


\subsection{Coleta de informações}

Após decisão de se ampliar o tema e o grupo de trabalho, elaboramos um roteiro de entrevista, que permitisse conhecer a percepção da equipe de enfermagem sobre a hospitalização da criança, que favorecesse uma visão mais ampla do grupo, de suas relações com a realidade contextual em que atuavam.

Comparecemos à unidade durante 10 dias para as entrevistas. Foram entrevistados 8 enfermeiros e 18 auxiliares de todos os turnos. As entrevistas foram feitas individualmente, com perguntas abertas e tentandose explorar todas as informações importantes e relacionadas com o estudo. Todas as entrevistas foram gravadas após consentimento do entrevistado e o tempo da entrevista variou entre 15 a 45 minutos cada.

\subsection{Organização dos dados}

Inicialmente as entrevistas foram transcritas na íntegra.

Procuramos destacar todas as idéias que, direta ou indiretamente, se relacionavam com o tema ou que se constituiriam em instrumentos potenciais para a fase seguinte.

Fizemos um agrupamento por pergunta e categorizamos os dados de forma a favorecer a compreensão do grupo.

Foram mantidas as formas de expressão de cada um e incluídas no material as observações das admissões feitas na 1 a etapa.

\subsection{Devolução do material ao grupo}

Após coleta de dados procuramos manter contatos periódicos com o grupo, informando-lhes do andamento do trabalho. Neste ínterim, verificamos a inviabilidade de iniciarmos a devolução dos dados aos dois grupos entrevistados. Optamos, assim, por começarmos apenas com os enfermeiros. Foi explicado a todos os motivos da restrição aos enfermeiros.

Por esta ocasião o hospital passava por uma séria crise de pessoal (demissões, transferências), o que nos levou a adiar o processo de discussões em grupo.

Posteriormente, procuramos conhecer os enfermeiros recém-admitidos e esclarecer-lhes sobre nossas pretensões. Entregamos os dados colhidos anteriormente, organizados em apostila, com o pedido de que fosse lida com antecedência. Após, marcamos a $1^{\text {a }}$. reunião para vermos como o grupo reagiria ao material e para discutirmos o interesse para a continuação do trabalho.

Conseqüentes a esta tivemos mais 11 reuniões, só com os enfermeiros e cujos resultados passaremos a relatar.

\section{APRESENTAÇ̃̃o E ANÁLISE dO TRABALHO COM O GRUPO}

Pretendemos implementar uma análise crítica do processo evolutivo ocorrido com o grupo de enfermeiros em relação à práxis, ao longo da pesquisa participante. Como a mesma se processa através da interação pesquisador/pesquisados e esta interação acontece desde a $1^{\text {a }}$ etapa da pesquisa, sentimos necessidade de analisarmos fatos ocorridos durante todo o transcurso da pesquisa.

Nos $1^{\text {os }}$ contatos com os enfermeiros, ao fazermos observações das admissões e ao conversarmos com os mesmos, já verificávamos contradições entre o que verbalizavam e o que estavam fazendo. Por exemplo, em uma das admissões a enfermeira não entrevistou a mãe nem elaborou o plano de cuidados pertinente. No entanto, ao ser questionada, disse: Acho que precisa conversar mais com a mãe, obter mais informações sobre a criança." ... "Os planos de cuidados de enfermagem são vergonhosos, baseados apenas em prescrições médicas. Precisam melhorar cientificamente".

Nesta mesma ocasião, um dos enfermeiros verbalizou:

"Gostaria de falar algo que não disse na outra entrevista. Creio que se deve dar maior relevãncia para a admissão da criança. Ela não é valorizada... não é dada nenhuma orientação nem apoio; não se ouve a criança." ... "A enfermagem que a recepciona deve cativar sua confiança, fazê-la sentir-se à vontade e segura em sua internação.'

Evidencia-se a mudança na percepção desta pessoa quanto à admissão da criança. Sua $1^{\text {a }}$. fala decorreu de uma visão individual, espontânea. $O$ fato de ter sido questionada, a forma como foi abordada e a discussão do tema em grupo levou-lhe a refletir e a reformular seus conceitos.

Os dados colhidos nas entrevistas individuais possibilitou-nos aprofundar mais o conhecimento do grupo. Tínhamos desde enfermeiros recém-formados até pessoas com mais de 20 anos de trabalho em pediatria. Verificamos, também, que a maioria delas não havia feito nenhum curso de atualização nos últimos 2 anos.

Pela pergunta "Como você se percebe na equipe em que trabalha?' indentificamos sérios problemas de relacionamento entre o grupo. Como se vê:

"As dificuldades que sinto são relacionadas às colegas... às vezes surge ciúme, desconfiança..."

"O relacionamento tanto comigo como com o pessoal auxiliar está ótimo... com excessâo das enfermeiras, porque o que a gente nota é um certo despeito...'

Para alguns também foi difícil responder:

"Ah, é muito difícil... não consegui me perceber muito bem."

"Fica difícil a gente ver a gente."

Pelas respostas sentimos que os enfermeiros, apesar de perseguirem um mesmo objetivo, encontra- 
vam-se desintegrados enquanto grupo.

Outros pontos mereceram nossa atenção. Ao manifestarem a percepção da criança e da mãe, entre outras coisas, disseram:

"A criança que está com a mãe dá mais trabalho; ela quer chamar atenção.'

"A criança que não está com a mãe é mais dócil; aceita tudo que a enfermeira vai fazer..."

"As mães, às vezes, têm um comportamento favorável, outras vezes apresentam um comportamento negativo, uma atitude de superproteção e prejudica a recuperação da criança.'

'Elas ficam reclamando pela mínima coisa; parece que querem repor o que faltou prá criança quando estava sã."

"A gente está vendo que a internação conjunta é ótima para a criança... Prá gente não foi tão bom porque a mãe exige um pouquinho mais.'

A forma de perceberem a mãe e a criança se revela, essencialmente, pelo comportamento de ambos na instituição. No entanto, nos parece que consideram esse comportamento sem se alertarem e refletirem sobre os motivos de sua ocorrência. Suas percepções baseiam-se nos ef eitos imediatos dos acontecimentos, dentro dos parâmetros do senso comum. Não se identifica uma tentativa de análise mais profunda sobre as reações da mãe e da criança frente à assistência recebida.

As respostas revelam uma postura acrítica do enfermeiro frente a seu objeto de trabalho.

Por outro lado, encontramos também falas bastante teóricas, com utilização de terminologia científica:

"A hospitalização eu acho uma coisa violenta, uma agressão que se faz à criança pela separação mãe-filho.'

Desse modo, supomos que não está havendo integração entre teoria e prática; elas coexistem mas desvinculadas uma da outra.

Através da pergunta " $O$ que você pensa que se poderia fazer em relação à hospitalização da criança?" confirmamos o interesse do grupo na continuidade do trabalho.

Implementamos a devolução dos dados, através de reuniões com discussões em grupo.

Nos reunimos no período entre abril a setembro de 1984, fazendo 12 reuniões ao todo; num tempo médio de 75 minutos cada reunião e com a participação de 6 elementos, em média.

Na medida em que progrediam na vivência do processo de práxis, através de discussões em grupo, percebíamos transformações ocorridas tanto a nível do discurso quanto em suas ações. $\mathrm{E}$ é isto que tentaremos apresentar e analisar a seguir.

1. reunião - grupo tenso; reunião serviu mais para desabafo.

- sobre o material disseram: - '... estão sendo destacados os problemas emocionais, psicológicos da criança hospitalizada.'
Vários problemas foram levantados e sugeridos para posterior encaminhamento. Verificamos que os enfermeiros sentiam os problemas da clínica só que cada um direcionando sua atenção para aspectos dispersos da realidade.

$2^{\text {a }}$ reunião- grupo muito emotivo

- revoltados pelo rodízio e deficiências

de pessoal

- discutiram dificuldades sentidas e programaram reunião com chefias.

Novamente, sentimos que a atitude do grupo, revelando superação de uma consciência isolada, individualizada para outra grupal, corporativa, tenha sido gerada pela vivência do processo de pesquisa participante, quando foi possível aos enfermeiros passarem da situação dos objetos a sujeitos da situação. Eles discutiam os problemas sentidos e encaminhavam soluções.

$\mathrm{Na} 4$ ? reunião começa-se a delinear o problema considerado prioritário: aspectos psicológicos da hospitalização da criança, só que com $1^{0}$. enfoque sobre a admissão. Surgiram muitos conflitos; muitas falas simultâneas. Neste sentido, tentamos moderar as decisões do grupo e oferecemos referencial bibliográfico sobre 0 assunto. Já surge a necessidade de preparo dos auxiliares de enfermagem para atuarem na admissão.

Neste ínterim desencadeia a greve e conseqüente desativação do hospital. Surge a proposta de aproveitarmos o tempo ocioso. Em 36 dias fizemos 6 reuniões, da $5^{\mathrm{a}}$. à $10^{\mathrm{a}}$ reunião.

Reuníamo-nos semanalmente o que favoreceu, a nosso ver, a organização da visão de mundo do grupo.

Muito se estudou e discutiu sobre o papel do enfermeiro dentro do sistema assistencial. A problemática da hospitalização da criança passa a ser vista de forma mais ampla e estrutural.

À medida que evoluíam neste processo percebíamos que a problemática da hospitalização da criança passa a ser vista de forma mais ampla e estrutural. Os enfermeiros demonstram uma postura analítico-crítica frente aos problemas levantados, principalmente, no que se refere à atuação do enfermeiro, em relação à:

- comunicação com a mãe

' Temos muita oportunidade de entrosar com a mãe e não aproveitamos. (...) Às vezes, é fuga o enfermeiro ficar mexendo com uma série de outras coisas..."

- comunicação com a criança

importante você se comunicar com a criança de acordo com a idade dela.'

- elaboração de planos de cuidados

' Precisamos tornar nossos planos mais respeitáveis... Em primeiro lugar torná-los mais decentes e em segundo, atualizá-los.'

- entre outras.

Somente no $8^{\circ}$. encontro se define como seria e quem executaria as diversas atividades propostas na nova admissão. Para isso foi necessário a superação de 
uma série de conflitos surgidos, ligados ao tema em pauta e, principalmente, em torno de quem faria a admissão; se seria atribuição só do enfermeiro, do enfermeiro e do auxiliar ou só do auxiliar.

Frente à coesão đa maioria, decidiram pela aplicação de um roteiro de admissão, quando o enfermeiro faria a entrevista com a mãe, um exame físico sumário da criança e elaboraria o plano de cuidados. Ao auxiliar caberiam as atividades já desempenhadas.

Nestes encontros fica premente a necessidade de preparo dos auxiliares. Como se vê:

"Está precisando um preparo para todos nós. As auxiliares estão reclamando...".

"Poderíamos discutir com os auxiliares para eles mesmos sentirem a necessidade de fazerem uma boa admissão. E nesta reunião, levantarmos as necessidades deles em termos de reciclagem."

Desse modo, iniciamos as reuniões com os auxiliares de enfermagem para:

- esclarecer sobre o andamento do trabalho

- pedir sugestões

- levantar necessidades para reciclagem.

Após reunirmos com o $2^{0}$. grupo resolvemos suspender devido a agudização da greve. 0 clima de tensão vivido não permitia nenhum trabalho paralelo.

Depois de um mês a situação voltou a se normalizar, com suspensão da greve e, novamente, nos reunimos para revermos o encaminhamento do trabalho.

11. reunião - surge nova necessidade.

"Sabe, estamos pensando em elaborar as rotinas da pediatria; é o mais urgente."

"Estamos pensando na elaboração das rotinas com a participação dos enfermeiros e auxiliares. Acho que será uma forma de estimular as pessoas a estudarem, a pesquisarem."

Por estas ocorrências, percebemos a expansão da consciência do grupo, quando se amplia a visão sobre o preparo dos auxiliares. Não pensavam mais em preparar algo e oferecer-lhes, mas em levá-los a estudarem junto com os enfermeiros.

A $12^{\text {a }}$. reunião foi coordenada pela enfermeira-coordenadora da unidade; nós participamos como membros e nesta reunião foram selecionados temas para a elaboração das rotinas e, novamente, se colocou a importância de se trabalhar junto com os auxiliares.

Nestas últimas reuniões percebíamos um bom clima nas discussões, sem agressões, quase não havendo falas superpostas, aparecendo até risos.

Como dito, o grupo foi capaz, por si só, de identificar seus problemas e destacar suas prioridades, sem a necessidade de nossa interferência, o que confirma o êxito da pesquisa participante.

O tema prioritário escolhido (admissão da criança), serviu apenas como fator desencadeador do processo participativo. A admissão da criança é limitante e envolve muitas outras dimensões - isto sendo descoberto devido à vivência do processo dialético estrutural.
À partir da admissão perceberam inadequações pessoais; questões internas a serem solucionadas; despreparo dos auxiliares e a necessidade de se implementar treinamento para os mesmos; entre outras coisas.

Várias mudanças foram percebidas no grupo:

- no relacionamento entre si e entre eles e os auxiliares;

- procuravam atender suas necessidades: faziam cursos de atualização em pediatria, apresentaram um trabalho em congresso, faziam reuniões regulares com auxiliares de enfermagem para discussão de assuntos pertinentes e era evidente a preocupação em se implementar o trabalho junto aos auxiliares.

Entretanto, estas mudanças não ocorreram de forma linear, simétrica, com todos os elementos do grupo. Alguns demonstravam desenvolver mais rapidamente que outros. Como exemplo temos a pouca ou nenhuma participação de enfermeiros recém-admitidos nas discussões grupais.

Outro enfermeiro, na $1^{\text {a }}$. reunião, disse:

"Não adianta discutir esta coisa, não. Vai ficar uma coisa só. Não temos com quem falar; todos se acomodam.'

Ao se decidir sobre a admissão, diz:

"Acho que a gente deve tentar, melhorar um pouquinho mais."

"Este roteiro é bom: o menino chega aí, fica jogado e você não sabe nada dele."

É visível a mudança quanto a seu comportamento no grupo e à sua percepção sobre o tema discutido. No entanto, continuam as contradições em suas falas e é nítida a dificuldade em associar conhecimentos teóricos à sua prática. Como se confirma:

"Acho que a admissão deveria ser feita pela enfermeira porque é um trabalho mais científico..."

"Está precisando um preparo para todos nós, enfermeiros e auxiliares de enfermagem."

Mas, ao se decidir por formas de preparo dos auxiliares, diz:

"Dar aulas não é comigo, não gosto."

Quanto à elaboração das rotinas:

"Acho importante, mas não vou fazer; não gosto, não tenho tempo."

Como se vê, no processo dialético, as pessoas vão e voltam; o processo de evolução da consciência se dá em espiral, num crescente. Neste sentido, parece-nos que alguns elementos do grupo talvez não tenham passado por nenhuma mudança perceptível. Porém, pelo fato de terem experienciado um processo educativo-participativo espera-se que alguma coisa em si tenha modificado: em suas percepçẽos, atitudes, etc., porque na práxis as pessoas passam por um vai e vem dentro do processo de transformação; elas recuam, mas nunca ao ponto em que estavam antes.

Assim, através da evolução do processo, ficou evidente as transformações ocorridas, tanto em termos pessoais como do grupo, apesar das diferenças individuais. A vivência no processo educativo-participativo, 
com valorização de princípios de ação democrática, levando-os a refletirem sobre suas ações, e pensarem suas contradições, impulsionou os enfermeiros na superação de uma práxis espontãnea, pasando para outra mais reflexiva.

Quanto a nós (pesquisadora), ao fazermos uma avaliação do processo vivido, identificamos mudanças em nossas posturas:

$$
\begin{aligned}
& \text { - como enfermeira; } \\
& \text { - como docente } \\
& \text { - como pessoa. }
\end{aligned}
$$

\section{CONCLUSÕES}

Como os resultados obtidos tornou-se evidente a efetividade da pesquisa participante, na capacitação dos enfermeiros que compuseram o grupo pesquisado. A vivência no processo educativo-participativo possibilitou ao grupo, maior integração: como pessoas, como grupo, em relação à chefias e subordinados e em relação à criança e pais.

A passagem de objetos a sujeitos da pesquisa, com as discussões promovidas, com participação nas resoluções, levou-os a melhor conhecer e interpretar a realidade da hospitalização da criança e a superar a execução alienada de suas funções, com o devido questionamento e reflexão sobre seus atos.

0 processo interativo com o grupo foi de aprendizagem contínua e mutúa, sendo possível detectarmos transformações ocorridas tanto em nós quanto nos pesquisados, apesar de que, no grupo, aconteceu mais rapidamente em uns que em outros.

Confirmou-se a importância da aplicação da pesquisa participante, orientada pela filosofia da práxis, através da evolução do processo e, especialmente, nas deciões finais tomadas, quando já demonstravam possuir uma visão mais estrutural da problemática da hospitalização da criança e ao emergir a necessidade de socializarem a experiência, numa busca constante de crescimento e integração. Tudo isto, acreditamos, reverterá em benefício da criança e família.

Confirmou-se, assim, a necessidade de procurarmos metodologias de pesquisa alternativas na enfermagem. Metodologias estas que procurem mais compreender que explicar os fatos e cujos trabalhos possam gerar resultados que revertam em benefício das populações estudadas.

"... O materialista é um eterno inconformado, porque a realidade não se fecha; a realidade é horizonte. A própria vida é linha do horizonte. (...) À medida que você marcha em direção ao horizonte ele vai se afastando e aí você vai divisando outras coisas, vai mostrando que as anteriores você superou... é o desafio... é outra postura de ciência."'

\section{REFERÊNCIAS BIBLIOGRÁFICAS}

1. BOTERF, G. LE. Pesquisa participante: propostas e reflexões metodológicas. In. BRANDÃO, C.R. Repensando a pesquisa participante. São Paulo, Brasiliense, 1984. p. 51-81.

2. GRAMSCI, A. Introdução à filosofia da práxis. Lisboa, Antídoto, 1978. $165 \mathrm{p}$.

3. INSTITUTO DE AÇÃO CULTURAL - IDAC - A observação participante, uma alternativa sociológica. Rio de Janeiro, CEI, 1978.

4. MENDONÇA, G.F. Ação educativa nos serviços básicos de saúde. In: ENCONTRO DE EXPERIÊNCIAS DE EDUCAÇÃO E SAÚDE DA REGIÃO NORDESTE. Anais... Brasília, Ministério da Saúde. Centro de Documentação, 1982. p. 9-14.

5. PINTO, J.B. Ação educativa através de um método participativo no setor saúde. In: ENCONTRO DE EXPERIÊNCIAS DE EDUCAÇÃO E SAÚDE DA REGIÃO NORDESTE. Anais... Brasília, Ministério da Saúde. Centro de Documentação, 1982. p. $15-9$.

6. VALLE, E.R.M. do. Aspectos psicológicos da recreação infantil, educação permanente de enfermeiras pediátricas num modelo de pesquisa de ação participante. Ribeirão Preto, Escola de Enfermagem, 1982. 182 p. Diss. mestr. 